doi:10.1016/j.scitotenv.2006.03.034

Copyright (c) 2006 Elsevier B.V. All rights reserved.

\title{
Long-term personal exposure to traffic-related air pollution among school children, a validation study
}

\section{Sofie Van Roosbroeck ${ }^{a}{ }^{*}$, Janine Wichmann ${ }^{b}$, Nicole A.H. Janssenc, Gerard Hoek $^{a}$, Joop H. van Wijnen ${ }^{d}$, Erik Lebret ${ }^{c}$ and Bert Brunekreef ${ }^{a}{ }^{e}$}

${ }^{a}$ Institute for Risk Assessment Sciences, Utrecht University, P.O. Box 80176, 3508 TD Utrecht, The Netherlands

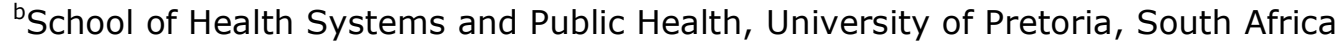

${ }^{\mathrm{C}}$ Center for Environmental Health Research, National Institute for Public Health and the Environment (RIVM), Bilthoven, The Netherlands

${ }^{\mathrm{d} D e p a r t m e n t}$ of Environmental Medicine, Municipal Health Service Amsterdam (GG\&GD), The Netherlands

eJulius Center for Health Sciences and Primary Care, University Medical Center

Utrecht, The Netherlands

Received 7 December 2005; revised 10 March 2006; accepted 23 March 2006. Available online 2 May 2006.

\begin{abstract}
Several recent studies suggest an association between long-term exposure to traffic-related air pollution and health. Most studies use indicators of exposure such as outdoor air pollution or traffic density on the street of residence. Little information is available about the validity of these measurements as an estimate of long-term personal exposure to traffic-related air pollution. In this pilot study, we assessed outdoor and personal exposure to traffic-related air pollution in children living in homes on streets with different degree of traffic intensity.
\end{abstract}

The personal exposure of 14 children aged 9-12 years to 'soot', $\mathrm{NO}_{x}$ ( $\mathrm{NO}$ and $\mathrm{NO}_{2}$ ) was assessed in Amsterdam between March and June 2003. Each child's personal exposure was monitored during four repeated 48 -h periods.

Concurrently, in- and outdoor $\mathrm{NO}_{x}$ measurements were carried out at the school and at the home of each participating child. Measurements were supplemented by a questionnaire on time activity patterns and possible indoor sources. Flowcontrolled battery operated pumps in a made-to-fit backpack were used to sample personal exposure to 'soot', determined from the reflectance of $\mathrm{PM}_{2.5}$ filters. Exposure to $\mathrm{NO}_{x}$ was assessed using Ogawa passive samplers. Children living near busy roads were found to have a $35 \%$ higher personal exposure to 'soot' than children living at an urban background location, despite that all children attended the same school that was located away from busy roads. Smaller contrasts in personal exposure were found for $\mathrm{NO}(14 \%), \mathrm{NO}_{2}(15 \%)$ and $\mathrm{NO}_{x}(14 \%)$. This finding supports the use of 'living near a busy road' as a measure of exposure in epidemiological studies on the effects of traffic-related air pollution in children.

Keywords: Air pollution; Traffic; Personal exposure; Validation; Children; Soot; Nitrogenoxides 


\section{Introduction}

Several recent studies show associations between air pollution and health (Brunekreef and Holgate, 2002). Results of three prospective cohort studies have suggested that long-term exposure to particulate matter (PM) air pollution is associated with increased mortality from respiratory and cardiovascular disease and lung cancer (Abbey et al., 1999, Dockery et al., 1993 and Pope et al., 1995). These studies have compared several large study regions with different ambient air pollution concentrations, on the assumption that exposure was uniform within each region.

Due to recent reports of a significant variation of outdoor traffic-related air pollution within cities, a Dutch cohort study assessed exposure to air pollution on a smaller spatial scale by taking the proximity to major roads into account using a geographic information system (GIS) (Hoek et al., 2002a). Participants who lived closer to major roads had a significantly increased risk of death resulting from cardiorespiratory causes (Hoek et al., 2002a).

Several cross-sectional studies have also shown associations between trafficrelated air pollution and adverse health effects (Delfino, 2002). These studies used indicators of exposure, such as traffic density on the street of residence, distance between the home and busy roads and/or estimated outdoor concentrations based on such characteristics. Little information, however, is available about the validity of these measurements as an estimate of long-term personal exposure to traffic-related air pollution.

The availability of validation data for short-term exposure studies is far more than that available for long-term monitoring. Several studies have documented that the temporal variation in outdoor particulate matter air pollution is reflected in temporal variation of personal exposure (Janssen et al., 1999 and Janssen et al., 2000). However, these studies do not provide information on the validity of outdoor air pollution concentrations for long-term exposure studies, which require spatial contrast in average outdoor air pollution.

A study conducted in the Netherlands at three schools near freeways with a range of traffic intensities from 45,000 to 150,000 cars/day showed significant differences in the long-term average personal nitrogen dioxide $\left(\mathrm{NO}_{2}\right)$ exposure of school children (Rijnders et al., 2001). Rijnders et al. found an estimated difference of $8.2 \mu \mathrm{g} / \mathrm{m}^{3}$ (SE 1.8 ) between personal $\mathrm{NO}_{2}$ exposure of the children attending the school with the highest and lowest traffic intensity; a difference of $46 \%$ (Rijnders et al., 2001). The increase in school outdoor $\mathrm{NO}_{2}$ for these children was $41 \%$, whereas the difference in home outdoor $\mathrm{NO}_{2}$ concentration was $28 \%$ (Rijnders et al., 2001). A study by Monn also focused on long-term exposure and showed highly significant correlations $\left(R^{2}>0.9\right)$ on a city-level between outdoor and personal annual mean estimates of exposure to $\mathrm{NO}_{2}$ (Monn, 2001). However, no long-term studies have involved personal sampling of the probably more relevant particulate matter, with a $50 \%$ cut off of $2.5 \mu \mathrm{m}$ in aerodynamic particle size $\left(\mathrm{PM}_{2.5}\right)$, and particulate components such as 'soot'. This lack of data hinders the interpretation of epidemiological studies on long-term air pollution exposures. In this pilot study we therefore aimed to evaluate the feasibility of personal monitoring for PM, since these procedures are known to be highly demanding for the participants. Since epidemiological studies on long-term effects of trafficrelated air pollution identify children as a sensitive group, we selected school children as participants in this study. We assessed personal exposure to trafficrelated air pollutants, $\mathrm{PM}_{2.5}$, 'soot', and $\mathrm{NO}_{x}$ in locations with varying degrees of traffic intensity. The overall objective of this study was to test the validity of 
traffic-related characteristics as an estimate for the personal long-term exposure to traffic-related air pollution, including $\mathrm{PM}_{2.5}$, 'soot' and $\mathrm{NO}_{x}$.

\section{Methods}

\subsection{Participant selection}

We conducted a pilot study in an urban background school in Amsterdam. With the cooperation of the school board, 40 children from grades 7 and 8 (9 to 12 years of age) were asked to participate in the study. These children received an invitation with a cover letter explaining the purpose of the study. Candidates were asked to return a participation form and parents had to sign an informed consent form.

\subsection{Study design}

Personal exposure to traffic-related air pollution was monitored 4 times per child in March, April, May and June of 2003. Children carried a personal $\mathrm{PM}_{2.5}$ sampler and an Ogawa passive sampler, to provide personal $\mathrm{NO}_{x}$ measurements, continuously for $48 \mathrm{~h}$. Concurrently, home indoor and outdoor measurements of $\mathrm{NO}_{x}$ and school indoor and outdoor $\mathrm{NO}_{x}$ and $\mathrm{PM}_{2.5}$ concentrations were collected using identical sampling equipment. Light absorbance was measured from all $\mathrm{PM}_{2.5}$ filters as a proxy for 'soot' or elemental carbon. Absorption coefficients of $\mathrm{PM}_{2.5}$ filters have been shown to be highly correlated with measurements of elemental carbon (EC) or 'soot' (Cyrys et al., 2003; N Janssen et al., 2001; NA Janssen et al., 2000 and Kinney et al., 2000). Elemental carbon or 'soot' is a product of incomplete combustion and has been found to correlate with diesel exhaust (Froschl and Niessner, 1997, Scheepers et al., 1995 and Scheepers and Velders, 1994). In this paper, absorption of the $\mathrm{PM}_{2.5}$ filters will be referred to as 'soot'.

Measurements took place from Monday to Wednesday or from Wednesday to Friday. In total, this study comprehended 8 measurement periods of $48 \mathrm{~h}$. During each measurement period five to nine personal measurements, their matching inand outdoor home measurements, and the in- and outdoor measurement at the school were conducted. Children lived in streets with varying traffic intensity. We ensured that samples for children living in streets with low and high traffic intensity were attained simultaneously.

\subsection{Sampling methods}

Personal $\mathrm{PM}_{2.5}$ measurements were conducted with $\mathrm{PM}_{2.5}$ GK2.05 cyclones (BGI Inc., Waltham, MA) that were designed and constructed for the EXPOLIS study (Koistinen et al., 1999) and flow-controlled battery operated pumps (BGI-400) at a flow rate of $4 \mathrm{l} / \mathrm{min}$. Batteries suitable for $48-\mathrm{h}$ sampling were used. Children could wear the sampler in a custom-made backpack which contained an internal sound isolation covering. We provided and distributed insulated boxes in which the backpack with the sampler could be placed in order to further reduce pump noise levels so that the noise would not disturb the participants over night. To assess personal $\mathrm{NO}, \mathrm{NO}_{2}$ and $\mathrm{NO}_{x}$, we used Ogawa passive samplers (Ogawa and Company USA, Inc.) with pre-coated $\mathrm{NO}_{2}$ and $\mathrm{NO}_{x}$ collection pads.

The personal measurements were started at the school, in order to motivate the group of children as a whole and to give detailed instructions on how to wear the sampling equipment. Children could wear the badge attached to their clothing using an alligator clip. Children were instructed to wear and keep the backpack 
and badge as close as possible. However, they were allowed to place the backpack with sampler nearby during indoor sedentary activities (watching TV, reading) or activities during which wearing the sampler would be too inconvenient or impossible (such as sleeping or swimming). Parents recorded the kind and duration of such activities, as well as the position of the backpack with sampler in a time activity questionnaire, which also collected data on housing conditions, daily activity patterns, school travel mode and possible indoor sources of $\mathrm{PM}_{2.5}$ and $\mathrm{NO}_{x}$.

Outdoor $\mathrm{PM}_{2.5}$ concentrations and 'soot' were measured using the same sampling equipment as used for the personal sampling measurements. For all $\mathrm{PM}_{2.5}$ measurements the same filters (Anderson Teflon $37 \mathrm{~mm}$ ) were used. Indoor and outdoor $\mathrm{NO}_{x}$ measurements were also carried out with the same sampler used for the personal sampling, however, for the outdoor measurements, a shelter was used to protect the badge from the weather. For all pollutants, at least one outdoor field blank per 48-h measurement period was collected.

\subsection{Analytical procedures}

The $\mathrm{PM}_{2.5}$ mass was determined by weighing a filter before and after sampling using a Mettler MT5 micro-balance (Mettler-Toledo, Greifensee, Switzerland) with $1 \mu \mathrm{g}$ reading precision. Filters were stored at $4{ }^{\circ} \mathrm{C}$ and were weighed after equilibrating for $24 \mathrm{~h}$ in a temperature $\left(20\right.$ to $23^{\circ} \mathrm{C}$ ) and humidity ( $30 \%$ to $40 \%$ ) controlled room. Details on the analytical procedures can be found elsewhere (Brunekreef et al., 2005; NA Janssen et al., 2000).

To assess light absorption of the $\mathrm{PM}_{2.5}$ mass, first reflectance was measured using an EEL 43 reflectometer, according to Standard Operating Procedures (SOP) developed for the ULTRA study (SOP ULTRA/KTL-L1.0) (Pekkanen et al., 2000) on the same filters used to determine $\mathrm{PM}_{2.5}$ mass. Each filter was measured at five standard spots and the average reflectance was calculated. Next, the reflectance of the $\mathrm{PM}_{2.5}$ filters was transformed into absorption coefficients (a) according to the following formula (ISO 9835, 1993):

$$
a=(A / 2 V) \square \ln \square\left(R_{0} / R_{\mathrm{s}}\right)
$$

where $A=$ loaded filter area $\left(\mathrm{m}^{2}\right), V=$ sampled volume $\left(\mathrm{m}^{3}\right), R_{0}=$ average reflectance of field blank filters, and $R_{\mathrm{s}}=$ reflectance of the sampled filter. Absorption coefficients were expressed in $\mathrm{m}^{-1} 10^{-5}$.

$\mathrm{NO}_{2}$ and $\mathrm{NO}_{x}$ were collected using precoated $\mathrm{NO}_{2}$ or $\mathrm{NO}_{x} 14.5-\mathrm{mm}$ pads ( $\mathrm{p} / \mathrm{Ns}$ PS114 and PS-124, Ogawa and Co Inc.) deployed in personal sampler bodies ( $\mathrm{p} / \mathrm{N}$ P-100, Ogawa and Co.). For the details on the sampling and analysis of the Ogawa passive samplers, we refer to the manufacturer's instructions (Ogawa USA, Inc., Pompano Beach, Florida, ogawausa.com) (Ogawa, 1998).

Pads were loaded into samplers and stored in airtight cups for transport to or from sampling sites. Following collection, samplers were refrigerated until analysed. Using a sulfanilamide solution and $\mathrm{N}$-(1-Naphthyl)-ethylenediamine dihydrochloride (NEDA) as colour producing reagent, the $\mathrm{NO}_{x}$ and $\mathrm{NO}_{2}$ concentrations were determined by an analysis based upon the Saltzman method, with a spectrometer at a wavelength of $545 \mathrm{~nm}$. NO concentrations were obtained by taking the difference of $\mathrm{NO}_{x}$ and $\mathrm{NO}_{2}$ concentrations.

\subsection{Traffic counts and meteorological data}


Data on traffic intensity were obtained from the Department of Infrastructure, Transport and Traffic, Amsterdam in The Netherlands. Data on wind direction per hour were obtained from the Royal Dutch Meteorological Institute (KNMI). The measurements were taken at the nearest measurement site, Amsterdam Schiphol airport, which is located south west of, and at about $10 \mathrm{~km}$ distance from the background school in the city center of Amsterdam. A home was considered down wind if the wind was directing within $60^{\circ}$ from the perpendicular line to the road in the direction of the home. For the measurements near a busy road, the percentage of time that the home was down wind from the road during the measurement was calculated. Next, these measurements were divided into two groups; one with down wind for more than $50 \%$ of the exposure time (i.e. longer than $24 \mathrm{~h}$ ) and one with less than $50 \%$ of the exposure time. Hence, the influence of wind direction on air pollution concentration for these two groups was assessed using multiple regression analysis.

\subsection{Statistical analysis}

The statistical analysis of the data was carried out using the statistical software program SAS (version 8e).

First, the distribution of personal, indoor and outdoor concentrations was obtained for the 'busy road' and 'background' groups separately. Definitions for the busy road group and the background group were designed taking the distribution of the proximity to busy roads of the participants into account. Accordingly, 'living near a busy road' was defined as living closer than $75 \mathrm{~m}$ to a road with traffic density of at least 10,000 cars/24 h. 'Living at a background location' was defined as living further away than $75 \mathrm{~m}$ from a road with traffic density of at least 10,000 cars $/ 24 \mathrm{~h}$. In urban settings, roads affect air pollution only at short distances, typically 50 to $100 \mathrm{~m}$ from a road. Ratios of the geometric means were calculated and differences between the groups were tested using a $t$-test. Next, the personal, indoor and outdoor concentrations of 'soot', $\mathrm{NO}, \mathrm{NO}_{2}$ and $\mathrm{NO}_{x}$ were logarithmically transformed to obtain normal distribution. Mixed effect model repeated measures analysis (proc mixed) was applied to perform a multiple regression model that included subject as a random factor that adjusted for repeated measurements of the same child.

Furthermore, results can be confounded by possible indoor sources, and different distribution of measurements over the sampling days. Therefore, adjustment for these variables was included in the regression model. As a result, the regression analysis used the logarithm of a pollutant concentration as a dependent variable and 'living near a busy road', exposure to environmental tobacco smoke (ETS) and cooking as independent binary variables.

To study the effect of possible outliers, Cook's $d$ values were calculated, and regression models were conducted again with the exception of main outliers of Cook's $d$.

\section{Results}

Fourteen children responded and enrolled into the study. All fourteen children completed the four 48 -h measurements. In total we collected 55 valid personal measurements for 'soot' and 41 for $\mathrm{NO}_{x}, 6$ in- and outdoor measurements at the school location, and 42 in- and outdoor measurements at the homes of the participants. The variation in proximity of busy roads to the residential addresses and the traffic intensity of these busy roads is shown in Table 1. Five children 
lived near a busy road, of which one (ID10) actually lived on a busy road $(14,400$ cars/24 h). The others lived at a background location.

Table 1.

Detailed information on the proximity to busy roads near the residential address

Participants living near a busy road are highlighted in grey. The distance to major roads was reflected as the distance from the door of the house to the middle of the road.

In general, children spent little time in traffic and little time outdoors. Median time spent in a car during $48 \mathrm{~h}$ was zero (with a $25-75 \%$ interquartile range of 0-0.75). The median time spent cycling was a little higher, $0.75 \mathrm{~h}$ (Q25$\mathrm{Q} 75=0-1.50)$. The median time spent outdoors, other than cycling, was $3.5 \mathrm{~h}$ (Q25-Q75 = 1.67-5.0). Of the 55 completed questionnaires, 18 reported an exposure to ETS, 37 reported an exposure to cooking, 8 reported an exposure to vacuum cleaning and 7 to dusting off. None of the participants reported having used a gas stove, heater nor fireplace.

No $\mathrm{PM}_{2.5}$ mass data are reported as we found unrealistically high concentrations in this study, likely due to cyclone malfunctioning. Visible coarse particles could be detected on some filters. The cyclone may not have been hooked tight enough to the backpack, therefore light physical activity of the participant could make the cyclone spin around and make the inlet of the pump point towards the participant's clothing instead of forward for short periods of time. In a further experiment we prevented the cyclone from spinning and normal $\mathrm{PM}_{2.5}$ mass date were reported. This interpretation is also supported by the results of school outdoor sampling, where the whole sampling set-up was firmly attached to an exterior school wall. The average school outdoor concentrations for $\mathrm{PM}_{2.5}$ mass and 'soot' were $10.8 \mu \mathrm{g} / \mathrm{m}^{3}$ and $0.95 \mathrm{~m}^{-1} 10^{-5}$ respectively, which can both be considered as regular background levels. When comparing this outdoor level to the average personal 'soot' concentration, we find an increase of only $30 \%$, (of which a part can be allocated to exposure to ETS) whereas the personal exposure to $\mathrm{PM}_{2.5}$ mass increases with an unrealistic factor 5 compared to the outdoor exposure. Further, higher personal 'soot' concentrations were found on days with elevated 'soot' levels in the outdoor air (we found a correlation coefficient of 0.98 between the personal 'soot' concentrations of the background group and the school outdoor 'soot' concentrations). This supports the reliability of the absorbance measurements.

The average reflectance of the field blank filter was $100.5(n=8$, S.D. 0.86$)$. The limit of detection (LOD), calculated as three times the standard deviation of the blanks, was $0.087 \mathrm{~m}^{-1} 10^{-5}$ for absorption; all absorption coefficients were above this LOD. The average field blank for $\mathrm{NO}_{x}$ was $6.91 \mathrm{ppb}(n=15, \mathrm{~S}$.D. $2.64)$, after exclusion of one very high field blank (28.65 ppb). For $\mathrm{NO}_{2}$ and $\mathrm{NO}$ the averages were $2.86 \mathrm{ppb}(n=16$, S.D. 2.23$)$ and $4.05 \mathrm{ppb}(n=15$, S.D. 2.47), respectively. The LOD was $7.93,6.68$ and $7.40 \mathrm{ppb}$ for $\mathrm{NO}_{x}, \mathrm{NO}_{2}$ and $\mathrm{NO}$, respectively. All values for $\mathrm{NO}_{2}$ and $\mathrm{NO}_{x}$ were above the LOD. With $\mathrm{NO}, 57 \%$ of the values were below the LOD. Therefore, we retained most values and only substituted the negative values $(0.03 \%)$ by zero.

Fig. 1 shows the distribution of the personal measurements of 'soot', $\mathrm{NO}, \mathrm{NO}_{2}$ and $\mathrm{NO}_{x}$ for the 'busy road' and 'background' group. In general, mean personal exposure to 'soot', $\mathrm{NO}, \mathrm{NO}_{2}$ and $\mathrm{NO}_{x}$ for children living near a busy road was higher than for the children living at a background location. 


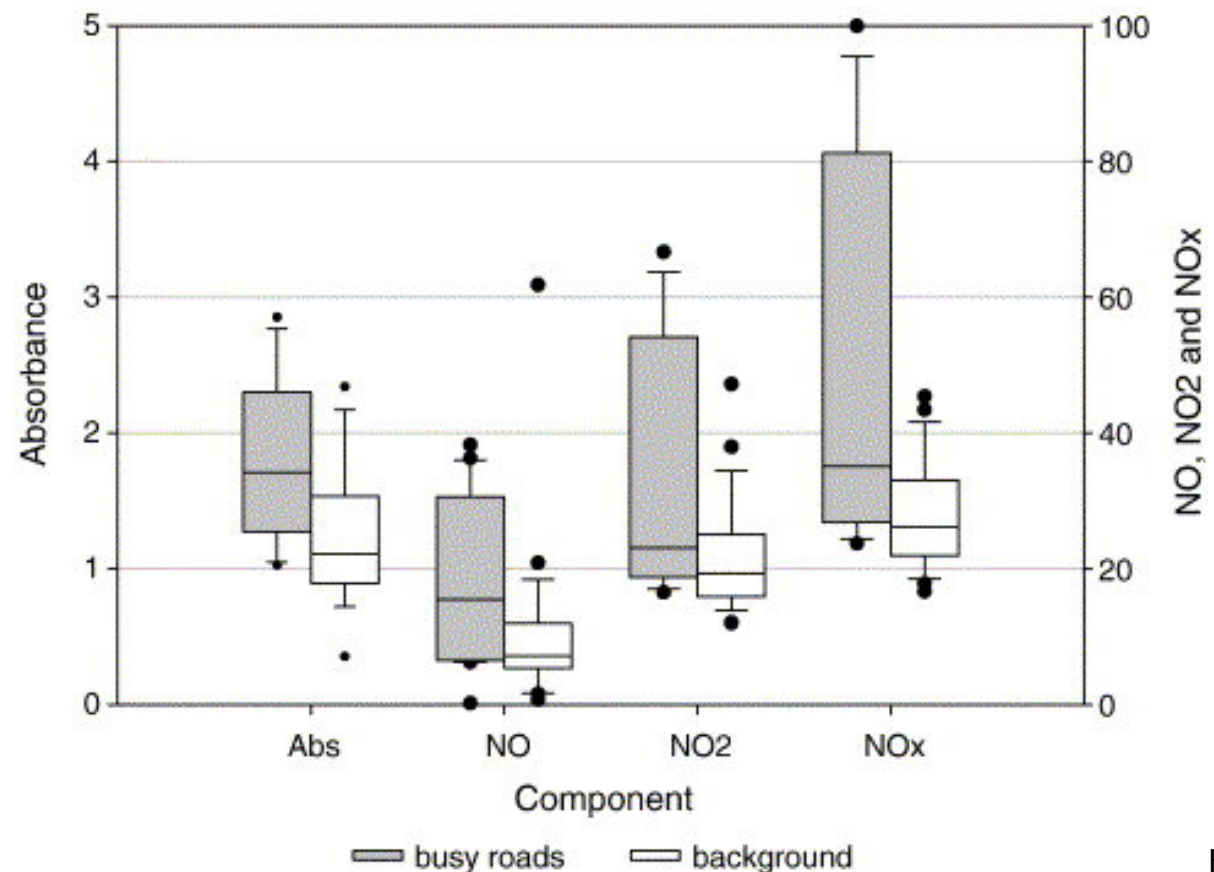

1. Distribution of personal exposure of 'soot' $\left(10^{-5} \mathrm{~m}^{-1}\right), \mathrm{NO}, \mathrm{NO}_{2}$ and $\mathrm{NO}_{x}(\mathrm{ppb})$ of children living near a busy road and children living at a background location. The scale of the figure was reduced to $100 \mathrm{ppb}$ for $\mathrm{NO}, \mathrm{NO}_{2}$ and $\mathrm{NO}_{x}$ for clarity reasons. Accordingly, three observations $\left(\mathrm{NO}_{x}\right.$ concentration of $185 \mathrm{ppb}$ and $109 \mathrm{ppb}$ and one NO concentration of $145 \mathrm{ppb}$ ) were not included in the figure.

A summary of the crude data is presented in Table 2 . We found a significant increase in $\mathrm{NO}$ and $\mathrm{NO}_{x}$ in the outdoor air for the busy road group compared to the background group. Elevated ratios were found for all home indoor pollutants, however they were not statistically significant. Table 2 further shows the results for the difference in exposure to the pollutants on the personal level. Comparable elevated ratios were found for $\mathrm{NO}, \mathrm{NO}_{2}$ and $\mathrm{NO}_{x}$; and a significant increase in personal 'soot' was found. The children from the busy road group had a $38 \%$ higher personal exposure to 'soot' compared to the children from the background group. Contrasts in the outdoor pollutant concentrations of the busy road group versus the background group were stronger for $\mathrm{NO}$ than for $\mathrm{NO}_{2}$.

Table 2.

Home outdoor, home indoor and personal pollutant concentrations for children living near a busy road and for children living at an urban background location

\begin{tabular}{|c|c|c|c|c|c|c|c|}
\hline & \multicolumn{6}{|c|}{ Geometric mean (min-max) } & \multirow{2}{*}{$\begin{array}{l}\text { Ratio of } \\
\text { geometric } \\
\text { means }\end{array}$} \\
\hline & $\boldsymbol{N}$ & \multicolumn{2}{|c|}{ Busy road group } & $\boldsymbol{N}$ & \multicolumn{2}{|c|}{ Background group } & \\
\hline \multicolumn{8}{|c|}{ Home outdoor } \\
\hline NO (ppb) & 15 & 7.69 & $(3.19-29.37)$ & 26 & 4.31 & $(1.41-21.12)$ & 1.78 \\
\hline $\mathrm{NO}_{2}(\mathrm{ppb})$ & 15 & 19.69 & $(14.44-26.84)$ & 27 & 17.81 & $(13.20-26.58)$ & 1.11 \\
\hline $\mathrm{NO}_{x}(\mathrm{ppb})$ & 15 & 28.22 & $(20.70-50.40)$ & 27 & 22.20 & $(12.31-39.65)$ & 1.27 \\
\hline
\end{tabular}




\begin{tabular}{|c|c|c|c|c|c|c|c|}
\hline & \multicolumn{6}{|c|}{ Geometric mean (min-max) } & \multirow{2}{*}{$\begin{array}{l}\text { Ratio of } \\
\text { geometric } \\
\text { means }\end{array}$} \\
\hline & $\boldsymbol{N}$ & \multicolumn{2}{|c|}{ Busy road group } & $\boldsymbol{N}$ & \multicolumn{2}{|c|}{ Background group } & \\
\hline \multicolumn{8}{|l|}{ Home indoor } \\
\hline NO (ppb) & 15 & 10.18 & $(1.03-43.82)$ & 24 & 8.50 & $(0.19-109.95)$ & 1.20 \\
\hline $\mathrm{NO}_{2}(\mathrm{ppb})$ & 15 & 24.53 & $(13.87-79.84)$ & 27 & 20.09 & $(11.25-69.41)$ & 1.22 \\
\hline $\mathrm{NO}_{x}(\mathrm{ppb})$ & 15 & 36.97 & $(18.36-123.97)$ & 27 & 30.88 & $(14.01-179.47)$ & 1.20 \\
\hline \multicolumn{8}{|l|}{ Personal } \\
\hline 'Soot' $\left(\mathrm{m}^{-1} 10^{-5}\right)$ & 20 & 1.70 & $(1.02-2.86)$ & 35 & 1.23 & $(0.44-2.56)$ & 1.38 \\
\hline NO (ppb) & 15 & 9.21 & $(0.19-38.09)$ & 25 & 7.69 & $(0.71-145.47)$ & 1.20 \\
\hline $\mathrm{NO}_{2}(\mathrm{ppb})$ & 15 & 24.29 & $(16.61-62.18)$ & 26 & 20.91 & $(11.94-46.99)$ & 1.16 \\
\hline $\mathrm{NO}_{x}(\mathrm{ppb})$ & 15 & 36.97 & $(23.81-100.48)$ & 26 & 30.88 & $(16.61-184.93)$ & 1.20 \\
\hline
\end{tabular}

Ratio of geometric means is the ratio of the overall geometric mean of the 'busy road' group versus the overall geometric mean of the 'background' group. $N$ is the number of 48 -h sampling periods.

t-test with $p<0.01$; for testing the difference of the distributions between the two groups.

Mean outdoor 'soot' measured at the school location was 0.95 (S.D. 0.20$) \mathrm{m}^{-1}$ $10^{-5}$. Mean $\mathrm{NO}_{x}$ concentration was 23.63 (S.D. 5.91) ppb outdoors, and 19.37 (S.D. 4.53) ppb indoors.

After adjustment for possible indoor combustion sources and day of measurement, the multiple regression model in Table 3 shows that the percentage increase in personal 'soot' of busy road children versus background children slightly decreases (35\% vs. $38 \%$ ), but it remained significant (Table 3 ). The percentage increase in outdoor NO slightly decreased (77\% vs. $75 \%)$ and the percentage increase in outdoor $\mathrm{NO}_{x}$ remained the same $(27 \%)$; both also remained statistically significant. Children exposed to ETS on a sampling day had a higher exposure to 'soot'; ETS had only little effect on personal $\mathrm{NO}_{x}$, and cooking had no effect on any of the measured pollutants. Taking ETS into account however, did not change the estimates for living on a busy road. 
Table 3.

Percentage increase in personal, home indoor and home outdoor 'soot', $\mathrm{NO}, \mathrm{NO}_{2}$ and $\mathrm{NO}_{x}$ exposure ( $95 \%$ confidence interval), when living near a busy road for adjusted and unadjusted model

\begin{tabular}{|l|l|l|l|l|}
\hline \multicolumn{2}{|l|}{} & Home outdoor & Home indoor & Personal \\
\hline 'Soot' & Unadjusted & $/$ & $/$ & $38(12,72)$ \\
\hline & Adjusted & $/$ & $/$ & $35(9,68)$ \\
\hline $\mathrm{NO}$ & Unadjusted & $77(16,169)$ & $20(-51,194)$ & $21(-46,161)$ \\
\hline & Adjusted & $75(12,175)$ & $21(-65,314)$ & $14(-49,156)$ \\
\hline $\mathrm{NO}_{2}$ & Unadjusted & $10(-2,25)$ & $23(-11,70)$ & $17(-10,51)$ \\
\hline & Adjusted & $10(-6,28)$ & $26(-28,120)$ & $15(-28,82)$ \\
\hline $\mathrm{NO}_{x}$ & Unadjusted & $27(8,44)$ & $20(-21,82)$ & $19(-14,67)$ \\
\hline & Adjusted & $27(4,55)$ & $22(-41,153)$ & $14(-35,97)$ \\
\hline
\end{tabular}

Multiple regression analysis; $\square<0.05$.

Regression results were adjusted for ETS, cooking, repeated measurements and different distribution of measurements over the sampling days.

'Soot' was sampled during 8 different sampling days, resulting in 55 measurements, whereas $\mathrm{NO}_{x}$ was sampled during 6 sampling days, due to delayed assembling of the $\mathrm{NO}_{x}$ badges and therefore resulting in less $\mathrm{NO}_{x}$ measurements (41). After excluding all 'soot' measurements on days that no $\mathrm{NO}_{x}$ concentrations were sampled, the percentage increase in personal 'soot' of busy road children versus background children decreased from $35 \%$ to $28 \%$ and it remained significant.

An outlier analysis using Cook's $d$ values showed that outliers did not influence the results; neither had sampling day an effect on the effect estimates.

Table 4 shows the increase in 'soot', $\mathrm{NO}_{2}, \mathrm{NO}$ and $\mathrm{NO}_{x}$ concentrations for the measurements during which the home is down wind for more and less than $50 \%$ of the sampling time. Both were compared to the measurements of children living at background locations that were sampled simultaneously. Out of the 55 personal measurements, 7 were sampled during sampling periods with more than $50 \%$ down wind, 13 with less than $50 \%$ down wind and 35 measurements were sampled in children living at background locations, all spread out over 8 sampling periods of $48 \mathrm{~h}$. On days with more than $50 \%$ down wind, children living at a busy road had a $54 \%$ higher personal exposure to 'soot' compared to background children. On days with less than $50 \%$ down wind the increase in personal exposure to 'soot' remains $31 \%$ for the busy road children. All increases in outdoor concentrations of $\mathrm{NO}, \mathrm{NO}_{2}$ and $\mathrm{NO}_{x}$ were statistically significant on days with more than $50 \%$ down wind. The increases for personal and home indoor concentrations were rather small and not statistically significant. 
Table 4.

Percentage increase (95\% confidence interval) in exposure to 'soot', $\mathrm{NO} \mathrm{NO}_{2}$ and $\mathrm{NO}_{x}$ for high and low percentage of time that the home is down wind from a major road

\begin{tabular}{|c|c|c|c|c|}
\hline & 'Soot' & No & $\mathrm{NO}_{2}$ & $\mathbf{N O}_{x}$ \\
\hline \multicolumn{5}{|l|}{ Home outdoor } \\
\hline$>50 \%$ down wind & / & $202(75,421)$ & $23(2,48)$ & $62(31,101)$ \\
\hline$<50 \%$ down wind & / & $36(-9,103)$ & $4(-10,20)$ & $12(-5,32)$ \\
\hline \multicolumn{5}{|l|}{ Home Indoor } \\
\hline$>50 \%$ down wind & / & $14(-76,432)$ & $14(-37,105)$ & $18(-45,153)$ \\
\hline$<50 \%$ down wind & / & $20(-67,331)$ & $27(-28,125)$ & $21(-40,146)$ \\
\hline \multicolumn{5}{|l|}{ Personal } \\
\hline$>50 \%$ down wind & $54(11,114)$ & $73(-47,467)$ & $4(-35,65)$ & $21(-34,120)$ \\
\hline$<50 \%$ down wind & $31(1,72)$ & $1(-59,148)$ & $15(-23,86)$ & $15(-32,93)$ \\
\hline
\end{tabular}

Multiple regression analysis; $\square<0.05$.

\section{Discussion}

A significant difference in personal exposure to 'soot' between children living near busy roads and children living at background locations in Amsterdam was found. This significant contrast could not be demonstrated for the indoor and personal concentrations of $\mathrm{NO}, \mathrm{NO}_{2}$ and $\mathrm{NO}_{x}$ in spite of significant differences in outdoor $\mathrm{NO}$ and $\mathrm{NO}_{x}$ concentrations.

The modest increase in personal exposure of children living near a busy road to 'soot' and especially $\mathrm{NO}_{2}$ and $\mathrm{NO}$ is partially related to the modest difference in traffic exposure. The children in the high exposed group of the current study lived within $75 \mathrm{~m}$ of a busy road with a traffic intensity of 10,000 cars/24 h. There was a $10 \%$ increase in outdoor $\mathrm{NO}_{2}$ and $75 \%$ in outdoor $\mathrm{NO}$ for children living near busy roads compared to those who were not. No outdoor 'soot' measurements were available. Rijnders et al. found an increase of $46 \%$ in personal exposure to $\mathrm{NO}_{2}$ for the children from the school located near the busiest highway $(169,637$ cars $/ 24 \mathrm{~h}$ ) compared to the children attending the school located near the relatively non-busy highway $(45,129 \mathrm{cars} / 24 \mathrm{~h}$ ) (Rijnders et al., 2001). The school outdoor $\mathrm{NO}_{2}$ was increased by $41 \%$ and the home outdoor $\mathrm{NO}_{2}$ concentration was increased by $28 \%$ (Rijnders et al., 2001). A study by RoordaKnape et al. selected residential districts within $300 \mathrm{~m}$ from a major motorway with traffic intensities varying from 80,000 to 152,000 cars/24 h (Roorda-Knape et al., 1998). They found differences of $56 \%$ and $40 \%$ in exposure to outdoor $\mathrm{NO}_{2}$ when comparing measurements in two different city districts at different distances (15 to 305 and 32 to $260 \mathrm{~m}$ respectively) from the roadside. The differences in outdoor 'soot' were $100 \%$ in one city district and $40 \%$ in the other. A study by Fischer et al., also conducted in the center of Amsterdam, performed 
measurements at 'low' and 'high' traffic homes, where 'high traffic home' was defined as a home right on a main street with average traffic intensity of 16,800 (Fischer et al., 2000). Differences in outdoor $\mathrm{NO}_{2}$ and 'soot' were about $25 \%$ and $75 \%$ respectively. Several other traffic-related air pollution studies performed measurements at school sites near roads with even higher traffic intensities (Janssen et al., 2001 and Kim et al., 2004). Kim et al. measured among other pollutants, $\mathrm{NO}$ and $\mathrm{NO}_{2}$ at 10 schools during several seasons (Kim et al., 2004). They found differences in concentrations between schools distant and nearby freeways with average traffic intensity of $170,000 \mathrm{cars} / 24 \mathrm{~h}$. Outdoor concentrations of $\mathrm{NO}_{2}$ varied from $20.5 \mathrm{ppb}$ for the schools without a major traffic source to 25.2 for the schools near the freeways. For NO measurements were 17.3 and $31.0 \mathrm{ppb}$ respectively. This results in outdoor differences of $23 \%$ for $\mathrm{NO}_{2}, 80 \%$ for $\mathrm{NO}$ and $22 \%$ for 'soot'. When compared to our findings, these differences for the outdoor measurements were overall higher for $\mathrm{NO}_{2}$ and comparable for NO.

Recently, two French studies concurrently assessed personal exposure to $\mathrm{PM}_{2.5}$ while monitoring outdoor levels of the same or similar pollutants (Gauvin et al., 2002 and Nerriere et al., 2005). In the framework of the VESTA study, personal exposures to $\mathrm{PM}_{2.5}$ of children in French urban environments and outdoor $\mathrm{PM}_{10}$ levels were assessed simultaneously (Gauvin et al., 2002). They evaluated the relative contribution of outdoor and indoor sources to personal exposure and concluded that proximity of the home to urban traffic emissions was a main determinant (Gauvin et al., 2002). The significant differences in personal exposure to 'soot' between children living near busy roads or not from the recent study are in agreement with these findings.

Difference in personal 'soot' was significant, while the personal $\mathrm{NO}_{2}$ and $\mathrm{NO}$ concentrations were not. Fischer et al. had documented that the outdoor contrast for pollutants like 'soot' in the city of Amsterdam was substantially larger than for $\mathrm{NO}_{2}$ (about $75 \%$ vs. $25 \%$ ), which is a secondary pollutant, and therefore it has a more homogeneous spatial distribution (Fischer et al., 2000). Indeed, in the current study the contrast in outdoor $\mathrm{NO}_{2}$ was only $10 \%$. The differences for $\mathrm{NO}$ were larger than for $\mathrm{NO}_{2}$ in the outdoor air. This is as expected since $\mathrm{NO}$ is a primary pollutant and more reactive and $\mathrm{NO}_{2}$ a secondary one. $\mathrm{NO}_{x}$ emitted from motorized traffic is largely emitted as NO and therefore, contrasts in exposure, related to living near a busy road, are expected to be larger for $\mathrm{NO}$ than for $\mathrm{NO}_{2}$. The small indoor and personal difference in $\mathrm{NO}$ is probably due to indoor sources and the reactivity of NO. Indoor and personal $\mathrm{NO}_{x}$ concentrations exceed outdoor $\mathrm{NO}_{x}$ concentrations. The $95 \%$ confidence intervals found for home indoor and personal $\mathrm{NO}$ and $\mathrm{NO}_{x}$ concentrations were much larger than those for the outdoor concentrations, indicating a role for indoor sources. Götschi et al. demonstrated little impact of indoor sources on 'soot' (Götschi et al., 2002).

Reasons for the differences in significance between outdoor on the one hand and indoor and personal exposures on the other include the impact of indoor sources. Additionally, an outdoor sampler was either exclusively exposed to low or high levels, whereas a child living near a busy road was probably exposed to both high levels at home and low levels at school.

One of the limitations of this study is that we did not succeed in collecting reliable $\mathrm{PM}_{2.5}$ mass. However, in the recent study, 'soot' and $\mathrm{NO}_{x}$ were used as specific markers for traffic-related air pollution. Particle mass ( $\mathrm{PM}_{2.5}$ mass) however, was only aimed to be included in order to allow comparisons with previous studies on traffic-related air pollution, as it is not considered to be a very specific indicator for traffic-related air pollution (Fischer et al., 2000), and has also been reported 
to underestimate spatial variation of traffic-related air pollution (Hoek et al., 2002b). Furthermore, the sampling of coarse particles has not affected 'soot' concentrations, since there's only a minor difference in assessing absorbance on $\mathrm{PM}_{10}$ collected filters than on $\mathrm{PM}_{2.5}$ collected filters (Cyrys et al., 2003 and Fischer et al., 2000).

Although wind data came from the nearest measurement site possible, the KNMI describes the scenery of the measurement site as predominantly grass and farmland mixed with infrastructure and buildings. The wind data of this site do not necessarily reflect the wind data for individual streets, as the architectural situation is more complex. Thus, the results of the wind direction analysis should be carefully considered.

Another point for discussion is to what extent the 4-month monitoring design is suitable for long-term exposure assessment. Obtaining long-term average personal exposures is complicated because of the demanding nature of personal monitoring for PM, the number of repeated measurements needs to be limited to a number that is realistic and feasible for the participants. Thus, the absolute concentrations of pollutants may not be representative for long-term averages. However, the focus of the comparison is the spatial contrast of exposure.

Therefore, the design was accurately carried out to make sure that concurrently five to nine 48-h measurements were performed on the same day in participants from both exposure groups.

\section{Conclusion}

Measuring long-term average personal exposure to traffic-related air pollution is complicated, because of the highly demanding nature of personal monitoring for particulate matter. The current design, however, succeeded in assessing whether the average personal exposure of children living near busy roads differed from those living at background locations. The results of this pilot study show that personal exposure to traffic-related particles is significantly higher for children living along busy roads, despite the fact that all participating children spent a substantial amount of time at the same school, located away from busy roads. This finding supports the use of 'living along a busy road' as a measure of exposure in epidemiological studies on the effects of traffic-related air pollution. It is still unclear, however, whether this conclusion will hold for populations other than children.

\section{Acknowledgements}

The authors would like to thank all the young participants, their parents and their teachers. Wichmann J. received a Dutch Huygens Scholarship during 2002-2003.

\section{References}

Abbey et al., 1999 D.E. Abbey, N. Nishino, W.F. McDonnell, R.J. Burchette, S.F. Knutsen and W. Lawrence Beeson et al., Long-term inhalable particles and other air pollutants related to mortality in nonsmokers, Am J Respir Crit Care Med 159 (1999), pp. 373-382. 
Brunekreef and Holgate, 2002 B. Brunekreef and S.T. Holgate, Air pollution and health, Lancet 360 (2002), pp. 1233-1242.

Brunekreef et al., 2005 B. Brunekreef, N.A. Janssen, J.J. de Hartog, M. Oldenwening, K. Meliefste and G. Hoek et al., Personal, indoor, and outdoor exposures to PM2.5 and its components for groups of cardiovascular patients in Amsterdam and Helsinki, Res Rep Health Eff Inst 127 (2005), pp. 1-70 [discussion 71-79].

Cyrys et al., 2003 J. Cyrys, J. Heinrich, G. Hoek, K. Meliefste, M. Lewne and U. Gehring et al., Comparison between different traffic-related particle indicators: elemental carbon (EC), PM2.5 mass, and absorbance, J Expo Anal Environ Epidemiol 13 (2003), pp. 134-143.

Delfino, 2002 R.J. Delfino, Epidemiologic evidence for asthma and exposure to air toxics: linkages between occupational, indoor, and community air pollution research, Environ Health Perspect 110 (2002) (Suppl 4), pp. 573-589.

Dockery et al., 1993 D.W. Dockery, C.A. Pope III, X. Xu, J.D. Spengler, J.H. Ware and M.E. Fay et al., An association between air pollution and mortality in six U.S. cities, N Engl J Med 329 (1993), pp. 1753-1759.

Fischer et al., 2000 P. Fischer, G. Hoek, H.v. Reeuwijk, DJB, E. Lebret and J.V. Wijnen et al., Trafficrelated differences in outdoor and indoor concentrations of particles and volatile organic compounds in Amsterdam, Atmos Environ 34 (2000), pp. 3713-3722.

Froschl and Niessner, 1997 B. Froschl and R. Niessner, Urban aerosol analysis: is determination of 1nitropyrene equivalent to the quantification of carbon?, J Aerosol Sci 28 (1997), pp. S71-S72.

Gauvin et al., 2002 S. Gauvin, P. Reungoat, S. Cassadou, J. Déchenaux, I. Momas and J. Just et al., Contribution of indoor and outdoor environments to PM2.5 personal exposure of children - VESTA study, Sci Total Environ 297 (2002), pp. 175-181.

Götschi et al., 2002 T. Götschi, L. Oglesby, P. Mathys, C. Monn, N. Manalis and K. Koistinen et al., Comparison of black smoke and PM2.5 levels in indoor and outdoor environments of four European cities, Environ Sci Technol 36 (2002), pp. 1191-1197.

Hoek et al., 2002a G. Hoek, B. Brunekreef, S. Goldbohm, P. Fischer and P.A. van den Brandt, Association between mortality and indicators of traffic-related air pollution in the Netherlands: a cohort study, Lancet 360 (2002), pp. 1203-1209.

Hoek et al., 2002b G. Hoek, K. Meliefste, J. Cyrys, M. Lewné, T. Bellander and M. Brauer et al., Spatial variability of fine particle concentrations in three European areas, Atmos Environ 36 (2002), pp. 4077-4088.

ISO, 1993 ISO, Ambient air-determination of a black smoke index (ISO 9835), International Organization for Standardization (1993).

Janssen et al., 1999 N.A.H. Janssen, G. Hoek, H. Harssema and B. Brunekreef, Personal exposure to fine particles in children correlates closely with ambient fine particles, Arch Environ Health 54 (1999), pp. 95-101.

Janssen et al., 2000 N.A.H. Janssen, J.J. de Hartog, G. Hoek, B. Brunekreef, T. Lanki and K.L. Timonen et al., Personal exposure to fine particulate matter in elderly subjects: relation between personal, indoor, and outdoor concentrations, J Air Waste Manag Assoc 50 (2000), pp. 1133-1143.

Janssen et al., 2001 N.A.H. Janssen, P.V. Vliet, F. Aarts, H. Harssema and B. Brunekreef, Assessment of exposure to traffic related air pollution of children attending schools near motorways, Atmos Environ 35 (2001), pp. 3875-3884.

Kim et al., 2004 J.J. Kim, S. Smorodinsky, M. Lipsett, B.C. Singer, A.T. Hodgson and B. Ostro, Trafficrelated air pollution near busy roads: the East Bay Children's Respiratory Health Study, Am J Respir Crit Care Med 170 (2004), pp. 520-526. 
Kinney et al., 2000 P.L. Kinney, M. Aggarwal, M.E. Northridge, N.A. Janssen and P. Shepard, Airborne concentrations of PM(2.5) and diesel exhaust particles on Harlem sidewalks: a community-based pilot study, Environ Health Perspect 108 (2000), pp. 213-218.

Koistinen et al., 1999 K.J. Koistinen, A. Kouse, V. Tenhola, O. Hänninen, M.J. Jantunen and L. Oglesby et al., Fine particle (PM2.5) measurement methodology, quality assurance procedures, and pilot results of the EXPOLIS study, J Air Waste Manage Assoc 49 (1999), pp. 1212-1220.

Monn, $2001 \mathrm{C}$. Monn, Exposure assessment of air pollutants: a review on spatial heterogeneity and indoor/outdoor/personal exposure to suspended particulate matter, nitrogen dioxide and ozone, Atmos Environ 35 (2001), pp. 1-32.

Nerriere et al., 2005 E. Nerriere, D. Zmirou-Navier, O. Blanchard, I. Momas, J. Ladner and Y. Le Moullec et al., Can we use fixed ambient air monitors to estimate population long-term exposure to air pollutants? The case of spatial variability in the Genotox ER study, Environ Res 97 (2005), pp. 32-42.

Ogawa, 1998 Ogawa $\mathrm{C}$. $\mathrm{NO}, \mathrm{NO}_{2}, \mathrm{NO}_{x}$ and $\mathrm{SO}_{2}$ sampling protocol using the ogawa sampler. Accessed at www.agawausa.com in 2002. 1998.

Pekkanen et al., 2000 J. Pekkanen, K.L. Timonen, P. Tiittanen, M. Vallius, T. Lanki and H. Sinkko et al., ULTRA: exposure and risk assessment for fine and ultrafine particles in ambient air. Study manual and data book. B9/2000, KTL, National Public Health Institute, Kuopio (2000).

Pope et al., 1995 C.A. Pope III, M.J. Thun, M.M. Namboodiri, D.W. Dockery, J.S. Evans and F.E. Speizer et al., Particulate air pollution as a predictor of mortality in a prospective study of U.S. adults, Am J Respir Crit Care Med 151 (1995), pp. 669-674.

Rijnders et al., 2001 E. Rijnders, N.A. Janssen, P.H. van Vliet and B. Brunekreef, Personal and outdoor nitrogen dioxide concentrations in relation to degree of urbanization and traffic density, Environ Health Perspect 109 (2001) (Suppl 3), pp. 411-417.

Roorda-Knape et al., 1998 M. Roorda-Knape, N. Janssen, J.D. Hartog, P.V. Vliet, H. Harssema and B. Brunekreef, Air pollution from traffic in city districts near major motorways, Atmos Environ 32 (1998), pp. 1921-1930.

Scheepers and Velders, 1994 P.T. Scheepers and D.D. Velders, Gas chromatographic-mass spectrometric determination of nitro polycyclic aromatic hydrocarbons in airborne particulate matter from workplace atmospheres contaminated with diesel exhaust, J Chromatogr 677 (1994), pp. 107121.

Scheepers et al., 1995 P.T. Scheepers, M.H. Martens, D.D. Velders, P. Fijneman, M. van Kerkhoven and J. Noordhoek et al., 1-Nitropyrene as a marker for the mutagenicity of diesel exhaust-derived particulate matter in workplace atmospheres, Environ Mol Mutagen 25 (1995), pp. 134-147.

* Corresponding author. Tel.: +3130253 5400; fax: +31302539499. 